\title{
Análise de Permeabilidade e Porosidade nos depósitos das formações Presidente Prudente e Santo Anastácio como modelos análogos para reservatório.
}

\section{Bruna Husak*, Alessandro Batezelli.}

\section{Resumo}

Esta Iniciação Científica tem como finalidade uma análise petrofísica das camadas heterolíticas das formações Presidente Prudente e Santo Anastácio, pertencentes a Bacia Bauru. A permeabilidade e a porosidade das rochas dessas unidades serão obtidas através da análise de lâminas petrográficas, softwares e cálculos associados que possibilitam inferir a variação vertical destes parâmetros petrofísicos num modelo análogo de reservatório.

Palavras-chave: Petrofísica, Análogos de Reservatório, Bacia Bauru.

\section{Introdução}

A Formação Presidente Prudente concentra alguns dos depósitos sedimentares mais recentes da Bacia Bauru, sendo que estes representam um estágio avançado da evolução sedimentar da bacia, pois o ambiente fluvial meandrante arenoso da Formação representa um aumento da complexidade dos processos fluviais, que resulta em um conjunto de rochas baseado em siltitos arenosos, arenitos e arenitos conglomeráticos (FERNANDES \& COIMBRA, 2000).

A Formação Santo Anastácio ocorre no limite superior do Grupo Cauiá da Bacia, sendo constituída por arenitos finos, bem selecionados e maciços. Os sedimentos dessa unidade têm origem no retrabalhamento dos depósitos fluviais deste Grupo e foram depositados por agente eólico (FERNANDES \& COIMBRA, 1994).

Estas Formações possuem fácies eólicas, fluviais e paleossolos e, portanto, são úteis para os estudos de análise petrofísica como modelos análogos de reservatório através do conhecimento dos elementos arquitetônicos em que se baseiam, assim como as análises de lâminas petrográficas e utilização do programa Corel Draw e software Jmicrovision com cálculos associados.

\section{Resultados e Discussão}

Previamente à análise petrofísica, em campo foram coletados dados suficientes para a caracterização dos elementos arquitetônicos do afloramento base do estudo conforme (MIALL 1985), na qual foram definidos os elementos de acreção lateral e de depósitos finos que compõem o paleoambiente fluvial meandrante. A partir desta caracterização, foram confeccionadas cerca de 15 lâminas petrográficas majoritariamente formadas por diferentes paleossolos do elemento arquitetônico de depósitos finos. A partir da determinação da micropedologia, textura, granulometria e porosidade foram identificadas 3 microfácies: MF1: Paleossolos baseados num horizonte $B$ textural plânico com estrutura de areia quartzosa mal selecionada e presença de intensa bioturbação por meio de pedotúbulos, especificamente agrotúbulos que dão origem a uma porosidade secundária pontual de baixos valores.

MF2: Paleossolos baseados num horizonte B textural com estrutura de areia quartzosa fina a média, envolta ocasionalmente por uma matriz argilosa amorfa localizada e porosidade primária destruída por cimentação carbonática.
MF3: Paleossolos baseados num horizonte B espódico com estrutura de areia quartzosa muito fina envolta por matriz argilosa e porosidade secundária expressiva gerada por feições pedológicas que se transformaram em poros planares e ortocavidades de grandes dimensões. Os valores de porosidade das microfácies foram obtidos por meio do aperfeiçoamento de fotografias das lâminas petrográficas e geração de mosaicos que foram trabalhados no software JMicroVision, o qual estimou a porosidade absoluta dos mosaicos. Com estes resultados foi possível estabelecer a variação vertical da porosidade em relação as microfácies conforme Figura 1.

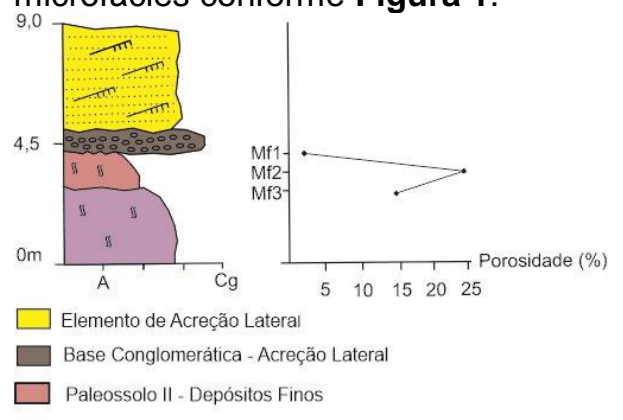

$\square$ Paleossolo I- Depósitos Finos

Figura 1. Variação vertical da porosidade absoluta das microfácies em relação com os elementos arquitetônicos.

\section{Conclusões}

As feições pedogenéticas como os pedotúbulos são os principais agentes da criação de porosidade secundária, que se pode apresentar de forma isolada quando associada a preenchimentos ou capeamentos de argila e/ou óxidos de Ferro ou de forma mais conectada quando favorecida por textura arenosa fina. Assim os processos deposicionais principalmente pedogenéticos influenciaram na porosidade e permeabilidade das rochas das formações Presidente Prudente e Santo Anastácio, de forma a apresentar uma grande variação vertical de porosidade e permeabilidade que caracteriza este reservatório.

\section{Agradecimentos}

FAPESP pelo financiamento do projeto 2015/17632-5, meu orientador Alessandro Batezelli e ao apoio financeiro SAE/CNPq.

MIALL, A. D. Architectural-element analysis: a new method of fácies analysis applied to fluvial deposits. Earth-Science Revies. V 22, n.4, p 261-308; 1985. FERNANDES, L. A; COIMBRA , A. M. 1994. O grupo Cauiá (Ks): Revisão Estratigráfica e contexto deposicional. Revista Brasileira de Geociências, São Paulo, v24 n.3, p. 164-176.

FERNANDES, L. A.; COIMBRA, A. M. 2000. Revisão estratigráfica da parte oriental da Bacia Bauru (Neocretáceo). Revista Brasileira de Geociências, São Paulo, v. 30, n.4, p. 717-728. 